\title{
Identification of potential transcriptionally active Copia LTR retrotransposons in Eucalyptus
}

\author{
Helena Marcon ${ }^{1,2^{*}}$, Douglas Domingues ${ }^{*^{*}}$, Celso Marino ${ }^{1 *}$ \\ From IUFRO Tree Biotechnology Conference 2011: From Genomes to Integration and Delivery \\ Arraial d'Ajuda, Bahia, Brazil. 26 June - 2 July 2011
}

\section{Background}

Long Terminal Repeat retrotransposons (LTR-RTs) represent the most abundant genomic component in all plant genomes thus far investigated. They are transposable elements that replicate through a "copy/paste" mechanism that relies on reverse transcription and integration of a RNA intermediate. Plant LTR-RTs can be divided in two major superfamilies: Copia and Gypsy[1]. LTR-RTs have impact on genome size variation, as well as in the expression of adjacent genes in their host genomes, providing a "genomic plasticity" [2]. Their transcription was believed to be extremely repressed in plants. However, despite their potential mutagenic and deleterious effects, LTR-RTs were proven to be transcriptionally active in several plant species [3].

Eucalyptus is one of the most commercially important forest genus in the world, due to their superior growth, broad adaptability and multipurpose wood properties. Most molecular studies in Eucalyptus are focused on cellulose production and wood development, and there are few works on genome composition, structure and evolution. Pinus and Populus, the tree genera with most available genomic resources, have several works analyzing their repertoire of LTR-RTs [i. e 4, 5], but only one study characterized LTR-RTs in Eucalyptus[6], with no detailed manual checking or phylogenetic analysis. Here, we used FOREST database as a starting point to identify transcriptionally active Copia LTR-RTs in Eucalyptus, that were further analyzed regarding their in silico expression, evolutionary diversity, and distribution in public genomic databases.

\begin{abstract}
Methods
A previous survey with 88 CopiaLTR-RTs from diverse plants defined six major common evolutionary Copialineages [7]. The 22 Arabidopsis thaliana families analyzed in that study were used as queries to the identify EucalyptusEST sequences related to Copiaelements in FORESTS database [8], by tBLASTx (e-value >1e-50). Sequences were then analyzed in RepBase [9] to confirm their similarity to Copia LTR-RTs. EucalyptusESTs with $>200 \mathrm{bp}$ of copia-like retrotransposon fragments were used to identify complete copies in Eucalyptusgrandis genome v 1.0 in a BLASTn search (identity $>80 \%$; in a region $>250 \mathrm{bp}$ ). We picked up $10000 \mathrm{bp}$ surrounding the aligned region, that were analyzed using LTR-Finder [10] and LTR_STRUC [11]. Full-length LTR-RTs were then used as queries in GenBank to retrieve related EucalyptusEST sequences ( $>200 \mathrm{bp} ;>80 \%$ identity). Phylogenetic analyses using the reverse transcriptase of these elements (alignment in MUSCLE, Maximimum Likelihood method, bootstrap 1000 replicates) were done using MEGA 5.01 [12].
\end{abstract}

\section{Results}

Stem, calli and seedlings were the cDNA libraries from FOREST database with most EST sequences, in this Copia LTR-RT search. We identified 20 consensus sequences (total: 36 ESTs) from 3 tissues, roots, leaves and flower-buds. We also identified 29 ESTs in GenBank from xylem, root apex and cold-stressed plants (Table 1). Using EST data, we identified six full-length retrotransposons families that had different copy number in the Eucalyptus genome, estimated by BLAST searches (cutoff 1e-50). Copy number ranged from 24 to 262 (Table 1). Phylogenetic analyses showed that they are members of the Ale, Angela, GMR and Ivana evolutionary lineages (figure 1). Ale was the evolutionary

\footnotetext{
* Correspondence: clmarino@ibb.unesp.br

${ }^{1}$ Departamento de Genética, UNESP, Botucatu, São Paulo, Brazil
}

Full list of author information is available at the end of the article 
Table 1 Overall features of LTR-RTs analyzed.

\begin{tabular}{ccccc}
\hline Family & Lineage & Genomic copy number & FOREST cDNA libraries & GenBank cDNA libraries \\
\hline RTE_copia_Eu_1 & Ale & 28 & seedlings & xylem \\
RTE_copia_Eu_2 & Ale & 262 & roots, leaves & xylem \\
RTE_copia_Eu_3 & Ale & 24 & root & xylem, cold-stressed \\
RTE_copia_Eu_4 & Angela & 243 & seedlings, calli & xylem \\
RTE_copia_Eu_5 & Ivana & 54 & leaves, root, calli, wood & xylem \\
RTE_copia_Eu_6 & GMR & 63 & leaves, seedlings & xylem \\
\hline
\end{tabular}

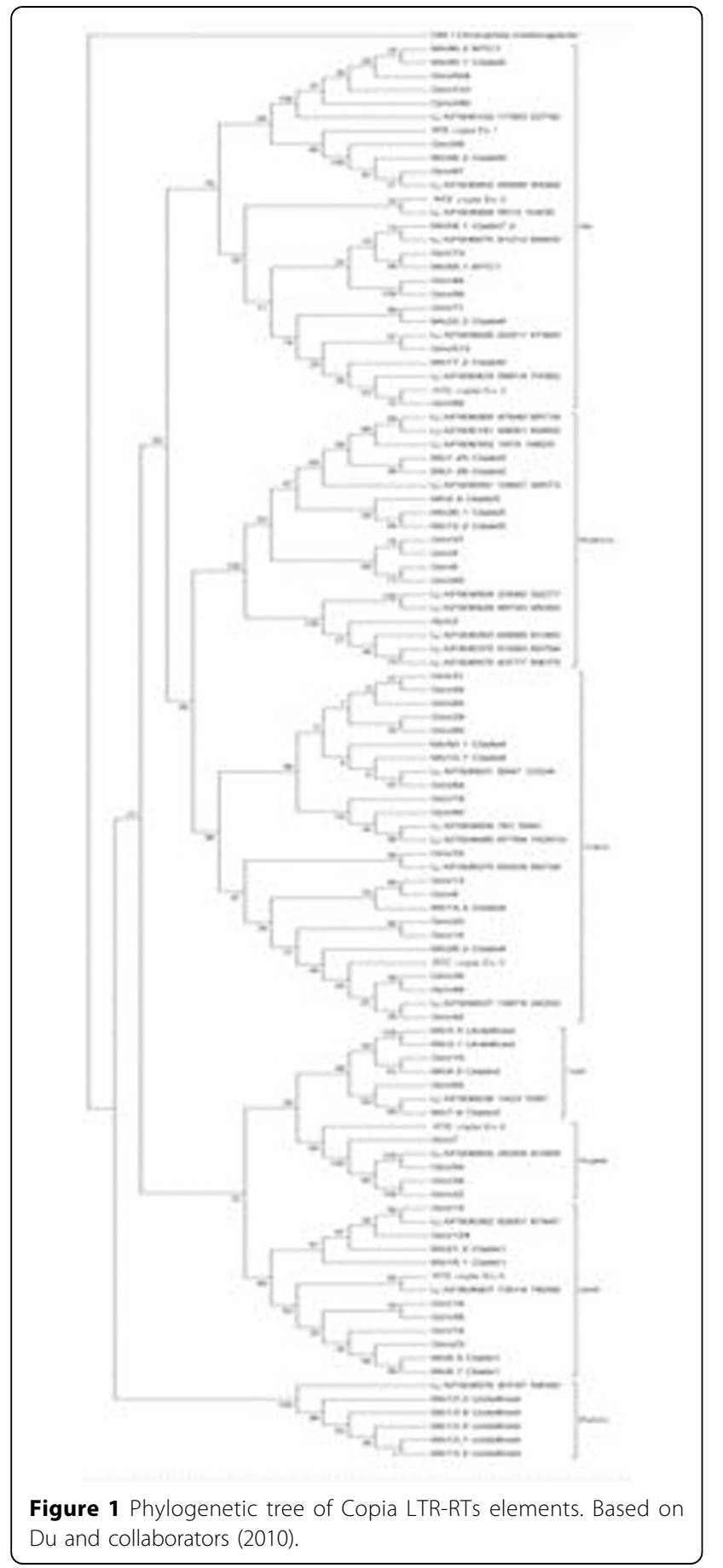

lineage encompassing families with highest and lowest copy number (Table 1 ).

\section{Conclusion}

In summary, the present data demonstrate the potential impact of future studies about functional and genomic analysis of LTR-RTs in Eucalyptus. This is the first characterization of full-length Copia LTR-RTs families in Eucalyptus genome with potential transcriptional activity, giving insights about phylogenetic diversity and copy number variation of retrotransposons in this tree.

\section{Acknowledgements}

HSM was supported by a fellowship from Coordenadoria de Aperfeiçoamento de Pessoal de Nível Superior (CAPES) and CNPq.

\section{Author details}

'Departamento de Genética, UNESP, Botucatu, São Paulo, Brazil. ${ }^{2}$ IAPAR, Londrina, Paraná, Brazil.

Published: 13 September 2011

\section{References}

1. Wicker T, Sabot F, Hua-Van A, Bennetzen JL, Capy P, Chalhoub B, Flavell A, Leroy P, Morgante M, Panaud O, Paux E, SanMiguel P, Schulman AH: A unified classification system for eukaryotic transposable elements. Nat Rev 2007, 8:973-982

2. Du J, Tian Z, Hans CS, Laten HM, Cannon SB, Jackson SA, Shoemaker RC, $\mathrm{Ma} \mathrm{J}$ : Evolutionary conservation, diversity and specificity of LTRretrotransposons in flowering plants: insights from genome-wide analysis and multi-specific comparison. Plant J 2010, 63:584-598.

3. Vicient CM, Jaaskelainen MJ, Kalendar R, Schulman AH: Active retrotransposons are a common feature of grass genomes. Plant Phys 2001, 125:1283-1292.

4. L'Homme Y, Séguin A, Tremblay FM: Different classes of retrotransposons in coniferous spruce species. Genome 2000, 43(6):1084-1089.

5. Zhou F, Xu Y: RepPop: a database for repetitive elements in Populus trichocarpa. BMC Genomics 2009, 10:14-23.

6. Bacci Júnior M, Soares RBS, Tajara E, Ambar G, Fischer CN, Guilherme IR, Costa EP, Miranda VFO: Identification and frequency of transposable elements in Eucalyptus. Genet Mol Biol 2005, 28(3):634-639.

7. Wicker T, Keller B: Genome-wide comparative analysis of retrotansposons in Triticeae, rice, and Arabidopsis reveals conserved ancient evolutionary lineages and distinct dynamics of individual copia families. Genome Research 2007, 17:1072-1081.

8. Vicentini R, Sassaki FT, Gimenes MA, Maia IG, Menossi M: In silico evaluation of the Eucalyptus transcriptome. Gen Mol Biol 2005, 28:487-495.

9. Jurka J, Kapitonov W, Pavlicek A, Klonowski P, Kohany O, Walichiewicz J: Repbase Update, a database of eukaryotic repetitive elements. Cytogenetics and Genome Research 2005, 110:462-467.

10. $\mathrm{Xu}$ Z, Wang H: LTR_FINDER: an efficient tool for the prediction of fulllength LTR retrotransposons. Nuc Acids Res 2007, 35:265-268. 
11. MCCarthy EM, MCDonald JF: LTR STRUC: a novel search and identification program for LTR retrotransposons. Bioinformatics 2003, 19:362-367.

12. Tamura K, Peterson D, Peterson N, Stecher G, Nei M, Kumar S: MEGA5:

Molecular Evolutionary Genetics Analysis using Maximum Likelihood,

Evolutionary Distance, and Maximum Parsimony Methods. Mol Biol Evol 2011, (submitted).

doi:10.1186/1753-6561-5-S7-P164

Cite this article as: Marcon et al: Identification of potential

transcriptionally active Copia LTR retrotransposons in Eucalyptus. BMC

Proceedings 2011 5(Suppl 7):P164.

Submit your next manuscript to BioMed Central and take full advantage of:

- Convenient online submission

- Thorough peer review

- No space constraints or color figure charges

- Immediate publication on acceptance

- Inclusion in PubMed, CAS, Scopus and Google Scholar

- Research which is freely available for redistribution

Submit your manuscript at www.biomedcentral.com/submit
C Biomed Central 